\title{
Evasão das Mulheres dos Cursos de Computação: Um estudo de Caso na Paraíba
}

\author{
Angelina S. da S. Sales ${ }^{12}$, Luana S. Reis ${ }^{12}, M^{a}$ Dayane F. C. Lima $^{12}$, Danielle R. D. Silva ${ }^{12}$ \\ ${ }^{1}$ Departamento de Informática - Universidade Federal da Paraíba (UFPB) \\ ${ }^{2}$ Centro de Informática - CI/UFPB \\ angelina.sales@cc.ci.ufpb.br, luanasreis@live.com,dayane20msn@hotmail.com, danielle@ci.ufpb.br
}

\begin{abstract}
Gender inequality in the context of Science and Technology $(C \& T)$, in particular in Computing, has become a concern for researchers worldwide. Studies show that even with incentive policies for the insertion of women in computing areas, their participation in courses is still very small. In a case study in the Paraíba, it can be seen that there are only incentive programs for enrollment, and this has not been shown to be sufficient to prevent the circumvention of women in computer courses.
\end{abstract}

Resumo. A desigualdade de gênero no contexto da Ciência e Tecnologia $(C \& T)$, em particular na Computação, têm se tornado uma preocupação para pesquisadores do mundo inteiro. Estudos mostram que mesmo com políticas de incentivos para a inserção das mulheres em áreas de computação, sua participação em cursos ainda é muito pequena. Em um estudo de caso na na Paraíba, pôde-se perceber que há apenas programas de incentivo ao ingresso, $e$ isto, têm-se mostrado não ser suficiente para impedir a evasão de mulheres nos cursos de computação.

\section{Introdução}

No último levantamento do IBGE, a quantidade de mulheres que atuam no setor de Tecnologia da Informação (TI), representam apenas um quarto das 520 mil pessoas na área. Segundo Olinto, as mulheres são levadas a fazer escolhas e seguir caminhos marcadamente diferentes daqueles escolhidos ou seguidos pelos homens. O presente estudo investiga as possíveis causas da evasão dos cursos de computação e tenta identificar as motivações das alunas que permaneceram no curso, uma vez que diversos fatores podem influenciar na permanência ou não nos cursos. A pesquisa foi subdividida em duas etapas, na primeira foi feito um levantamento dos dados das alunas ingressantes e desistentes, a fim de identificar um fator comum que as fizeram desativar a matrícula, na segunda etapa foram realizadas entrevistas online com alunas que estão prestes a concluir os cursos, visando encontrar, também, um fator comum que as fizeram permanecer. 


\section{Um estudo de Caso na Paraíba}

Acompanhando a tendência mundial, também na Paraíba, há uma grande disparidade de gênero entre os estudantes dos cursos de Computação. Para tentar diminuir esse quadro, na Paraíba já existem projetos que visam o incentivo do ingresso das mulheres nas áreas relacionadas a computação.

Neste estudo de caso, estudamos a taxa de evasão apenas dos cursos de Ciência da Computação, Engenharia da Computação e Matemática Computacional, a fim de comparar a disparidade de ingressantes e desistentes quando comparados por gênero.

Num levantamento de dados dos últimos 5 anos, de 2012 até 2016, considerando as duas as chamadas anuais dos 3 cursos estudados. Foi constatado que houveram 1.520 estudantes ingressantes no total e esse montante, apenas 200 deles eram estudantes do gênero feminino, o correspondente à aproximadamente $13,16 \%$.

A média do ingresso de estudantes do gênero feminino no curso de Ciência da Computação (CC) quase se mantém constante, oscilando muito pouco de 2012 até 2015, porém, em 2016, o número de estudantes do gênero feminino que se matricularam no curso cai para quase a metade (Gráfico 1). Analisando o gráfico 2, verifica-se que o número de estudantes do gênero feminino inscritas no curso de Engenharia de Computação (EC) mostrou-se crescente até 2014, o que pode ser justificado pela alteração na forma de ingresso da instituição, no qual passou de vestibular para ENEM. No entanto, nos anos seguintes, o inverso acontece e a média de estudantes do gênero feminino ingressantes passa a cair, quando comparado aos anos anteriores.

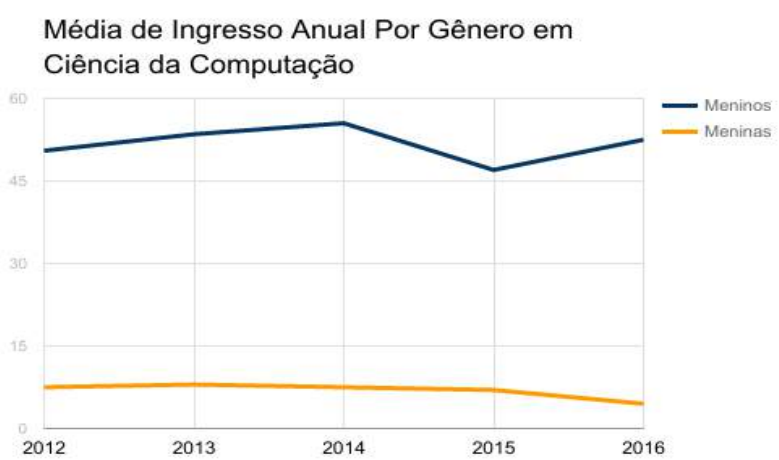

Gráfico 1. Média de Ingresso em CC

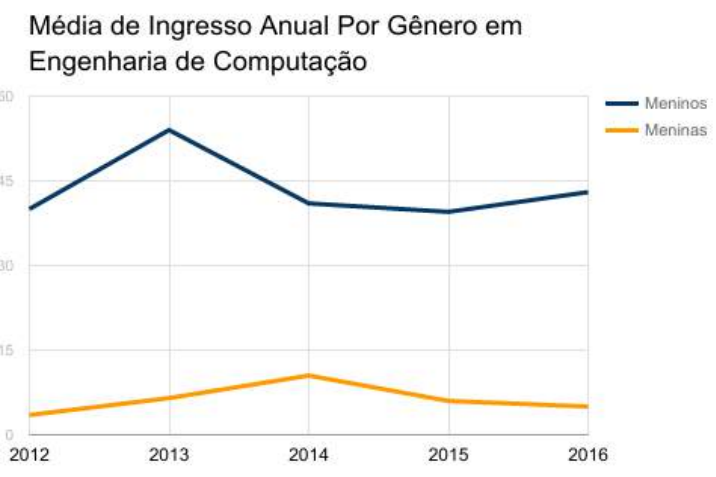

Gráfico 2. Média de Ingresso em EC

O número de estudantes do gênero masculino que se matricularam se intensifica com o passar dos anos em CC, ao contrário das estudantes do gênero feminino, tendo uma queda no número de matrículas em 2015, mas, em 2016 volta a aumentar, como pode-se observar no Gráfico

Em EC, algo semelhante acontece com a média de estudantes do gênero masculino ingressantes, no qual, em 2013 apresentou um pico de crescimento considerável, em seguida, essa média baixa um pouco, retomando o crescimento de matrículas em 2014, oscila um pouco em 2015, mas logo volta a crescer em 2016 (Gráfico 2). Já o curso de Matemática Computacional (MC), tem apresentado os piores índices de ingressantes em ambos sexos, quando comparados aos outros 2 cursos. Todavia, ao contrário dos outros cursos, MC tem 
apresentado uma média de estudantes do gênero feminino ingressantes decrescente até 2015 e passa a crescer em 2016. Já o número de estudantes do gênero masculino que se matricularam aumenta até 2015 e em 2016, a média baixa (Gráfico 3).

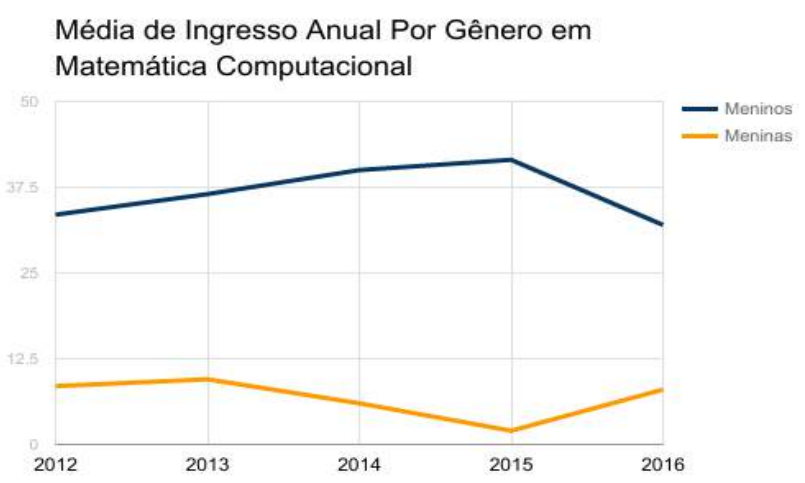

\section{Gráfico 3. Média de Ingresso em MC}

$\mathrm{Na}$ totalidade dos 1.520 estudantes que se matricularam nos cursos ofertados, apenas $55,13 \%$ ainda estão ativas e só $11,1 \%$ pertencem às estudantes do gênero feminino.

Embora o número de desistentes seja alto para ambos os sexos, a porcentagem maior da evasão dos cursos ainda é predominantemente feminina. Em uma pesquisa realizada em 2014 (Gráfico 4), pode-se perceber a taxa de retenção dos cursos.

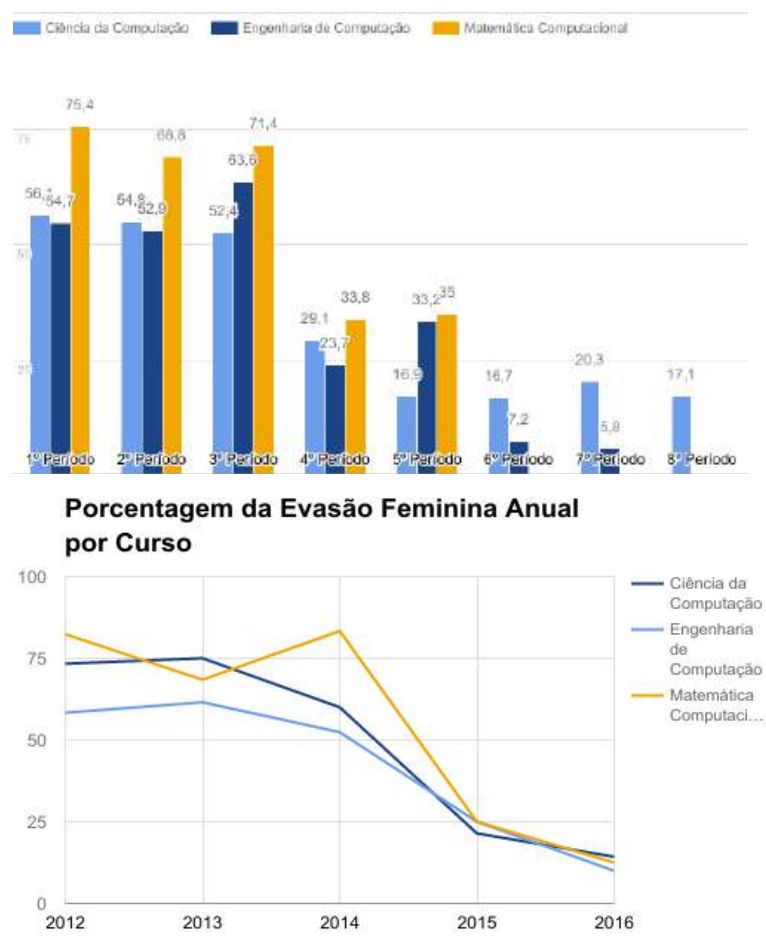

Gráfico 4. Taxa de Retenção dos Cursos do CI. Gráfico 5. Porcentagem da Evasão Feminina

Essa retenção é calculada em função reprovação por média, reprovação por falta e trancamentos. E acredita-se que essa pesquisa ainda seja válida até hoje, visto que a estrutura dos componentes curriculares dos cursos estudados mudaram pouco ou quase nada até hoje. As disciplinas que apresentaram os maiores com índices de retenção são as disciplinas 
dos primeiros períodos, em especial, as voltadas para o ensino da programação. O que pode explicar a tendência decrescente do Gráfico 5, pois, a evasão é calculada pela razão entre o total de estudantes que abandonaram o curso pelo total de estudantes vinculados ao curso, não havendo indicação da desistência por período, acompanhando a trajetória das alunas. Mas cabe esclarecer que quem ingressou nos cursos a partir de 2013, ainda não houve tempo suficiente para concluir o curso, visto que a duração mínima para CC e MC são 8 períodos, o equivalente a 4 anos e para EC são 10 períodos, o equivalente a 5 anos e que o atual período letivo da universidade estudada ainda é 2016.2. O que nos leva a concluir que o problema de evasão é preocupante, ainda mais considerando a demanda atual e futura por profissionais da área.

\section{Considerações Finais}

Apesar das medidas de incentivo ao ingresso só terem começado na Paraíba em 2013, de lá pra cá pouco se mudou no que diz respeito ao aumento da quantidade de estudantes do gênero feminino que ingressaram nos cursos. $O$ leve crescimento pode ser justificado pela alteração na forma de ingresso, que passou de vestibular convencional com algumas vagas reservadas para o ENEM para ENEM totalmente, o que pode justificar a volta do seu decréscimo, nos anos posteriores.

Os projetos existentes também não tem apresentado muitos resultados quanto a estimular a permanência das estudantes do gênero feminino que já ingressaram nos cursos de Ciência e Tecnologia, uma vez que a porcentagem de desistência dos cursos ainda é predominantemente feminina. No qual, aproximadamente $44 \%$ das estudantes do gênero feminino permanecem nos cursos, enquanto $62 \%$ dos estudantes do gênero masculino continuam com a matrícula ativa. A partir desses dados, pode-se perceber que embora existam muitos projetos de apoio e incentivo a inserção, esses, não têm se mostrado suficientes para equilibrar o quadro da disparidade de gênero no que diz respeito aos ingressantes dos cursos de computação. De forma geral, concluímos que deveriam existir incentivos à permanência, uma vez que não adianta inserir muitas estudantes do gênero feminino nos cursos, sem que se possa garantir a permanência das mesmas.

\section{Referências}

Censo Demográfico 2010. Trabalho e Rendimento. IBGE, 2012. Disponível em: <http://biblioteca.ibge.gov.br/visualizacao/periodicos/1075/cd_2010_trabalho_rendim ento_amostra.pdf>. Acesso em: 10 mar. 2017.

OLINTO, Gilda. A inclusão das mulheres nas carreiras de ciência e tecnologia no Brasil. Inc. Soc. Brasília, DF. 2011. pp 68-77. Disponível em: http://revista.ibict.br/inclusao/article/view/1667 Acesso em 20 de março de 2017. 